\title{
ESTUDO COMPARATIVO DA TRANSFORMAÇÃO AUSTENITA-FERRITA EM DOIS AÇOS IF COM DIFERENTES COMPOSIÇÕES QUIIMICAS*
}

Ana Luiza Soares Cezário ${ }^{1}$ Geraldo Lúcio de Faria²

\section{Resumo}

Os aços IF são livres de elementos intersticiais, como o $\mathrm{C}$ e $\circ \mathrm{N}$, na matriz ferrítica. Estes elementos são controlados no processo de refino na aciaria, a partir da aplicação de técnicas de desgaseificação a vácuo, juntamente com a adição de elementos estabilizantes, como $\mathrm{Ti}$ e $\mathrm{Nb}$. Durante a fabricação e em algumas aplicações dos aços IF, como por exemplo soldagem, a transformação de fase austenita $\rightarrow$ ferrita e o efeito dos elementos de liga na sua cinética têm forte influência na microestrutura final.Neste contexto, este trabalho caracterizou microestruturalmente e comparou as cinéticas de transformação de fase de dois tipos de aços IF com composições químicas diferentes, sendo eles o IF-Ti e o IFTiNb. Por meio dos resultados obtidos, foi possível concluir que o aço IF-TiNb, como fabricado, possui uma microestrutura mais refinada devido à presença do $\mathrm{Nb}$ e seu papel na laminação controlada do aço. Além disso, observou-se que as temperaturas críticas Ar3 e Ar1 do aço IF-TiNb são sistematicamente menores do que as temperaturas medidas para o aço IF-Ti. Como a fração dos elementos microligantes em solução sólida é muito pequena, atribui-se este efeito à diferença no teor de $\mathrm{Mn}$ dos aços estudados, que parece potencializar o refino de grão na etapa final de resfriamento da chapa de aço laminada.

Palavras-chave:Aços IF; Cinética de transformação de fase; Composição química.

\section{COMPARATIVE STUDY OF AUSTENITE-FERRITA TRANSFORMATION IN TWO IF STEELS WITH DIFFERENT CHEMICAL COMPOSITIONS}

\section{Abstract}

The IF steels are free of interstitial elements, such as $\mathrm{C}$ and $\mathrm{N}$, in the ferritic matrix, which are controlled during the steel refining process using vacuum degassing techniques, andstabilizing element additions ( $\mathrm{Ti}$ and $\mathrm{Nb}$ ). During the steel manufacturing and in some applications, welding for example, the austenite $\rightarrow$ ferrite phase transformation and the effect of the alloying elements on the phase transformation kinetics have strong influence on steel final microstructure. In this context, this work characterized the steel microstructures and compared the phase transformation kinetics of two types of IF steels with different chemical compositions: the IF-Ti and the IF-TiNb. The obtained results showed that the IF-TiNb steel has the finer microstructure due to the presence of $\mathrm{Nb}$ and its effect on controlled rolling. Besides that, it was observed that the critical temperatures Ar3 and Ar1 for the IF-TiNb steel are systematically smaller than the obtained for the IF-Ti steel. As the fraction of microalloying elements in solid solution is too low, the difference on studied steel Mn contents, possibly is the main cause of this. The Mn content seems to potentiate the ferritic grain refinement during the final steel cooling.

Keywords: IF steels; Kinetics of phase transformation; Chemical Composition.

1 Engenheira Metalúrgica, Mestranda em Engenharia de Materiais, Departamento de Engenharia Metalúrgica e de Materiais (DEMET), Universidade Federal de Ouro Preto (UFOP), Ouro Preto, Minas Gerais, Brasil.

2 Físico, Dr., Professor, DEMET, UFOP, Ouro Preto, Minas Gerais, Brasil. 


\section{INTRODUÇÃO}

A busca por aços que apresentam boa conformabilidade e elevada estampabilidade para a fabricação de peças com designs complexos vem sendo exigida por diversas aplicações em vários segmentos da indústria mundial desde a década de 70 . Nesse contexto, surgiram os aços IF, do inglês "interstitial free", ou seja, livre de elementos intersticiais na matriz ferrítica, como o C e o N. Estes elementos são controlados durante o processo de refino do aço na aciaria, a partir da aplicação de técnicas de desgaseificação a vácuo, juntamente com a adição de elementos estabilizantes, como Ti e Nb, capazes de formar carbonetos, nitretos e carbonitretos [1-3].

Em geral, o Ti quando adicionado na matriz ferrítica do aço IF captura o $\mathrm{N}$ e o $\mathrm{C}$ podendo formar precipitados do tipo: $\mathrm{TiN}, \mathrm{TiS}, \mathrm{Ti}_{4} \mathrm{C}_{2} \mathrm{~S}_{2}$ e TiC. Enquanto os aços IF estabilizados por $\mathrm{Ti}$ e $\mathrm{Nb}$ podem formar precipitados do tipo $(\mathrm{Nb}, \mathrm{Ti})_{4} \mathrm{C}_{2} \mathrm{~S}_{2}$, $\mathrm{TiC}$ e $\mathrm{NbC}$ e TiN [4]. Uma vez formados estes carbonetos, nitretos e carbonitretos, sua dissolução só voltará a acontecer caso os aços sejam aquecidos em temperaturas relativamente elevadas, onde a solubilidade destes elementos será significativa na austenita. Segundo a literatura, esta solubilidade passa a ser significativa para aços com $0,01 \%$ de $\mathrm{Nb}$, acima de $1000^{\circ} \mathrm{C}$. Para concentrações da ordem de $0,05 \%$ de $\mathrm{Nb}$, acima de $1150^{\circ} \mathrm{C}$. Para adições de Ti superiores a $0,04 \%$, a temperatura a partir da qual a dissolução dos nitretos acontece é superior a $1300^{\circ} \mathrm{C}$ [4-7].

Atualmente, o mercado mais relevante de aplicações para aços IF é o setor automobilístico que faz uso de processos de conformação mecânica a frio de chapas de aço IF para a fabricação de partes dos automóveis, porém, em outros, faz uso de procedimentos de soldagem, onde a austenitização e a transformação austenita $(\gamma)$ $\rightarrow$ ferrita $(\alpha)$ definirá a microestutura final de zonas termicamente afetadas[6-7].

Durante o processo de fabricação, e em algumas aplicações específicas como soldagem, os aços IF, em algum momento experimentarão a transformação de fase $\gamma \rightarrow \alpha$ que, em função do tamanho de grão das fases, partições químicas de elementos nas fases, entre outros aspectos, terá um impacto significativo na metalurgia do produto. $O$ efeito dos elementos microligantes na cinética de transformação de fases se reflete na sua microestrutura. $\mathrm{O} \mathrm{Nb}$, por exemplo, atrasa a decomposição austenítica, devido a presença de átomos de $\mathrm{Nb}$ dissolvidos em solução sólida e/ou precipitação de partículas finas de NbC que atuam como barreiras à migração dos contornos de grãos, promovendo uma estrutura mais refinada [8-10]. A adição de Ti favorece a precipitação de partículas mais grosseiras como $\mathrm{TiC}$ e $\mathrm{Ti}_{4} \mathrm{C}_{2} \mathrm{~S}_{2}$ que por sua vez afetam menos a temperatura de início de transformação $\gamma \rightarrow \alpha$ [9-11]. O Mn também é um dos elementos que merece especial atenção, pois se trata de um elemento $\gamma$-gêneo e, portanto, diminui a temperatura Ar3 retardando o início da decomposição austenítica[12].

Neste contexto, este trabalho propõe-se a comparar a cinética de transformação de fase de dois tipos de aços IF com composições químicas diferentes por meio da técnica de dilatometria que é uma das técnicas mais eficientes para o estudo das transformações defases no estado sólido das ligas ferrosas, pois permite o monitoramento, em tempo real, da evolução das fases em função das alterações dimensionais que ocorrem na amostra quando submetida a um ciclo térmico [4].

\section{MATERIAIS E MÉTODOS}

As atividades desenvolvidas neste trabalho foram divididas em duas etapas: a primeira consistiu na caracterização química e estrutural do estado de entrega de 
duas amostras de aços IF; a segunda consistiu no estudo da transformação de fase $\gamma \rightarrow \alpha$ dos aços IF por meio da técnica de dilatometria.

\subsection{Materiais}

Os materiais utilizados neste trabalho foram dois aços IF com composições químicas diferentes. Os aços foram denominados aço IF-Ti e aço IF-TiNb, sendo o primeiro estabilizado ao Ti e o segundo estabilizado com $\mathrm{Ti}$ e $\mathrm{Nb}$.

\subsection{Procedimentos Experimentais}

\subsubsection{Análise Química e Caracterização Microestrutural do Estado de Entrega}

A caracterização química foi realizada com o auxílio da técnica de Espectrometria de Emissão Óptica no equipamento Foundry-Master Xpert do fabricante Oxford Instruments, onde se determinou os principais elementos químicos constituintes das amostras.

As amostras foram microestruturalmente caracterizadas em seu estado de entrega a partir dos procedimentos padrão de preparação metalográfica de corte, embutimento, lixamento e polimento. Em seguida, foram atacadas com reativo químico Nital $2 \%$ para revelação da microestrutura. Posteriormente, as amostras dos aços IF em seu estado de entrega foram analisadas com o auxílio do microscópico óptico Leica modelo DM2700 M, onde obteve-se imagens para posterior medição do tamanho de grão ferrítico.

Posteriormente as amostras foram submetidas a ensaios de microdureza Vickers, segundo a norma ASTM E384, em um microdurômetro digital do fabricante Pantec utilizando-se uma carga de 50 gf e o tempo de aplicação de 10 s.

\subsubsection{Ensaios Dilatométricos}

Após a etapa de caracterização do estado de entrega, corpos de provas cilíndricos dos dois aços foram confeccionados com dimensões padronizadas de aproximadamente $10 \mathrm{~mm}$ de comprimento e $3 \mathrm{~mm}$ de diâmetro, conforme ilustrado pela Figura 1 (a). A Figura 1 (b) apresenta uma fotografia do corpo de prova, na qual pode-se observar também um termopar do tipo $\mathrm{K}$ soldado na superfície de um corpo de prova.

(a)
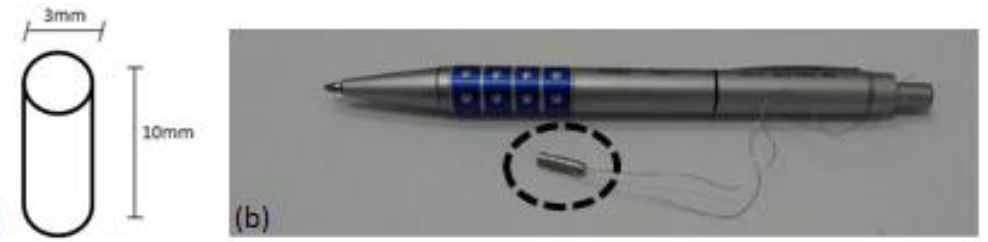

Figura 1 - (a) llustração do corpo de prova utilizado nos ensaios dilatométricos; (b) corpo de prova de dilatometria (tracejado) usinado a partir do aço IF com termopar do tipo K soldado na superfície.

Os ensaios de dilatometria foram realizados em um dilatômetro R.I.T.A. L78 do Laboratório de Tratamentos Térmicos e Microscopia Óptica (LTM) do DEMET/UFOP. A temperatura de austenitização dos dois aços foi de $1100^{\circ} \mathrm{C}$. Os ciclos térmicos aplicados são apresentados na Figura 2, na qual pode-se perceber a taxa de aquecimento $\left(5^{\circ} \mathrm{C} / \mathrm{s}\right)$, o tempo de austenitização (180s) e as diferentes taxas de resfriamento contínuo aplicadas para os dois aços. 
A partir de uma análise prévia dos resultados obtidos nos ensaios dilatométricos, algumas amostras dos aços IF, submetidas a taxas de resfriamento específicas, foram preparadas para análise microestrutural, conforme procedimento padrão de preparação metalográfica. Além disso, as amostras provenientes dos ensaios dilatométricos foram submetidas a ensaios de microdureza Vickers nas mesmas condições utilizadas para as amostras no estado de entrega.

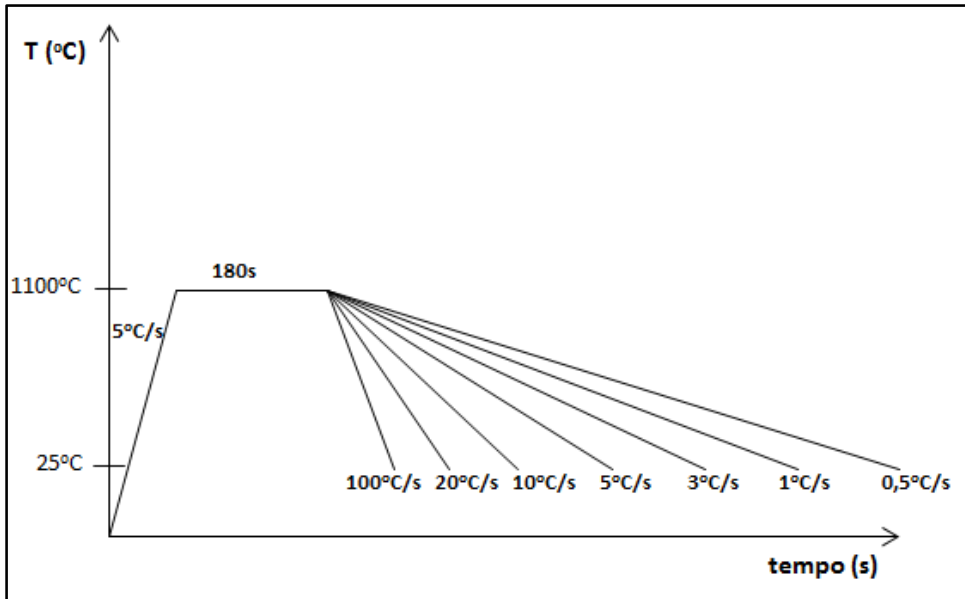

Figura 2 - Ciclos térmicos utilizados nos ensaios de dilatometria para os aços IF-Ti e IF-TiNb.

\section{RESULTADOS E DISCUSSÃO}

\subsection{Análise química}

A Tabela 1 apresenta a composição química dos aços estudados. Ressalta-se a quantidade do elemento estabilizante Ti no aço IF-Ti e as concentrações de $\mathrm{Ti}$ e $\mathrm{Nb}$ no aço IF-TiNb. Nota-se também, a diferença no teor de Mn dos aços. O aço IF-TiNb possui $0,67 \% \mathrm{Mn}$, enquanto que o aço IF-Ti apresenta $0,10 \% \mathrm{Mn}$.

Tabela 1 - Composição química dos aços IF-Ti e IF-TiNb estudados neste trabalho (\%massa).

\begin{tabular}{|c|c|c|c|c|c|c|c|c|c|}
\hline Aço & $\mathbf{C}$ & $\mathbf{S i}$ & $\mathbf{M n}$ & $\mathbf{P}$ & $\mathbf{S}$ & $\mathbf{A l}$ & $\mathbf{N b}$ & $\mathbf{T i}$ & Mo \\
\hline $\mathrm{IF}-\mathrm{Ti}$ & 0,004 & 0,028 & 0,10 & 0,013 & 0,010 & 0,03 & 0,0030 & 0,0577 & 0,0132 \\
\hline IF-TiNb & 0,004 & 0,014 & 0,67 & 0,028 & 0,011 & 0,02 & 0,0187 & 0,0172 & 0,0107 \\
\hline
\end{tabular}

\subsection{Caracterização Microestrutural do Estado de Entrega}

A Figura 3 apresenta as microestruturas dos aços IF estudados, na qual a Fig. 3 (a) e (b) corresponde a microestrutura do aço IF-Ti e a Fig.3 (c) e (d) ao aço IF-TiNb. Observa-se que ambos os aços são constituídos por uma matriz ferrítica, o que é esperado em função de suas composições químicas e processamento termomecânico experimentado durante a fabricação.

Nota-se claramente a diferença no tamanho médio dos grãos ferríticos, sendo que o aço IF-TiNb possui tamanho de grão de $6,0 \mu \mathrm{m}$ e a aço IF-Ti de $21,0 \mu \mathrm{m}$. Os aços IF$\mathrm{TiNb}$ apresentam grãos menores e mais irregulares do que os aços microligados somente com $\mathrm{Ti}$, que por sua vez apresentam uma estrutura ferrítica equiaxial. Este fato se deve, principalmente, ao efeito do ancoramento dos contornos de grãos ocasionado pelos átomos de $\mathrm{Nb}$ dissolvidos em solução sólida (aumento da temperatura de não recristalização durante a laminação controlada) e pela precipitação de $\mathrm{NbC}$ nos contornos de grãos durante a transformação, resultando 
em uma estrutura mais refinada, com uma maior densidade de contornos de grãos [8-9].

Além disso, os precipitados formados durante o processamento do aço IF-Ti, onde o C pode ser estabilizado pela formação de carbonetos (TiC) e/ou de carbossulfetos $\left(\mathrm{Ti}_{4} \mathrm{C}_{2} \mathrm{~S}_{2}\right)$, são mais grosseiros do que o precipitado $\mathrm{NbC}$ formado nos aços IF-TiNb. Com isso, os finos precipitados formados nos aços IF-TiNb distribuídos ao longo da microestrutura do material funcionam como barreiras mais efetivas à migração dos contornos de alto ângulo durante as etapas de recristalização e crescimento de grão durante o recozimento [10].

A microestrutura mais refinada do aço IF-TiNb se reflete diretamente nos resultados dos ensaios de microdureza Vickers, onde os valores medidos foram de 125HV para o IF-TiNb, enquanto que para o aço IF-Ti foi de 95HV.
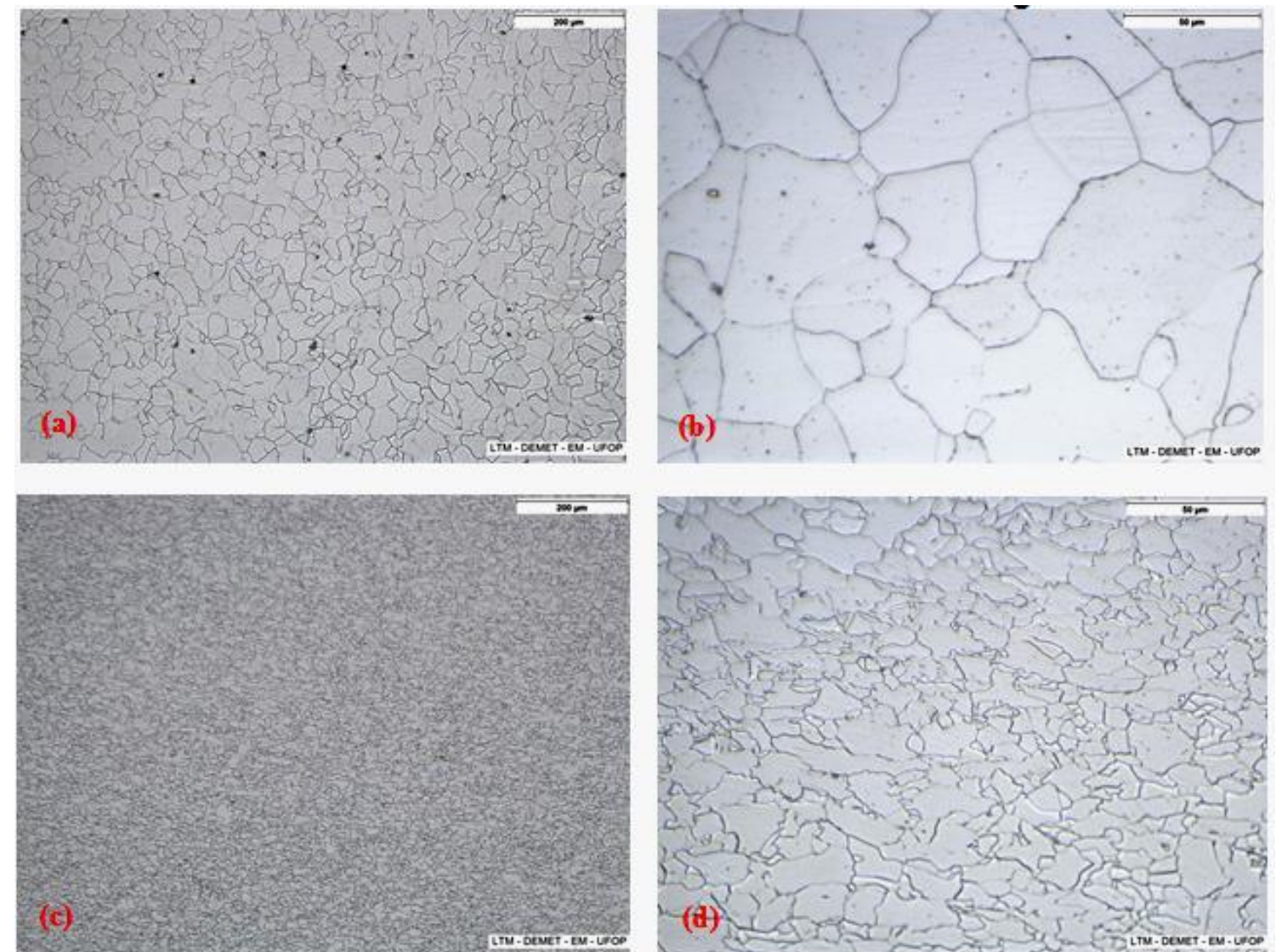

Figura 3 - Microestruturas do estado de entrega dos aços IF - MO - Nital 2\%: (a) IF-Ti aumento de 100x; (b) IF-Ti aumento de 500x; (c) IF-TiNb aumento de 100x e (d) IF-TiNb aumento de 500x.

\subsection{Ensaios Dilatométricos}

\subsubsection{Aquecimento contínuo}

A Figura 4 (a) apresenta um exemplo das curvas dilatométricas de aquecimento a uma taxa de $5^{\circ} \mathrm{C} / \mathrm{s}$ para os aços IF-Ti e IF-TiNb. A Figura 4 (b) apresenta as temperaturas críticas de início e fim da transformação $\alpha \rightarrow \gamma$ para os aços IF-Ti e IF$\mathrm{TiNb}$. A determinação das temperaturas críticas foi realizada aplicando-se o método das derivadas [13].

Nota-se que as médias das temperaturas críticas Ac1 e Ac3 para o aço IF-TiNb $\left(888^{\circ} \mathrm{C}\right.$ e $\left.1027^{\circ} \mathrm{C}\right)$ são ligeiramente menores em relação às do aço $\mathrm{IF}-\mathrm{Ti}\left(892^{\circ} \mathrm{C}\right.$ e 
$1028^{\circ} \mathrm{C}$ ). Isto pode ser explicado pelo fato da nucleação da $\gamma$ a partir da $\alpha$ ocorrer preferencialmente nos contornos de grãos ferríticos, dessa forma, uma estrutura inicialmente mais refinada terá uma maiordensidade de contornos de grãos e consequentemente a nucleação heterogênea será favorecida, resultando em uma menor temperatura de início de transformação $\alpha \rightarrow \gamma$ [14].

Considerando que a taxa de aquecimento foi constante, além de identificar as diferenças nas temperaturas críticas, foi possível medir o tempo total de transformação, sendo 27,2s para o aço IF-Ti e 27,8s para o aço IF-TiNb. Percebe-se que apesar da transformação começar antecipadamente no aço IF-TiNb, em função do favorecimento da etapa de nucleação, o efeito da adição do $\mathrm{Nb}$, como descrito na literatura, parece dificultar os processos difusionais, prejudicando a etapa de crescimento da austenita, justificando assim o maior tempo de austenitização [10].

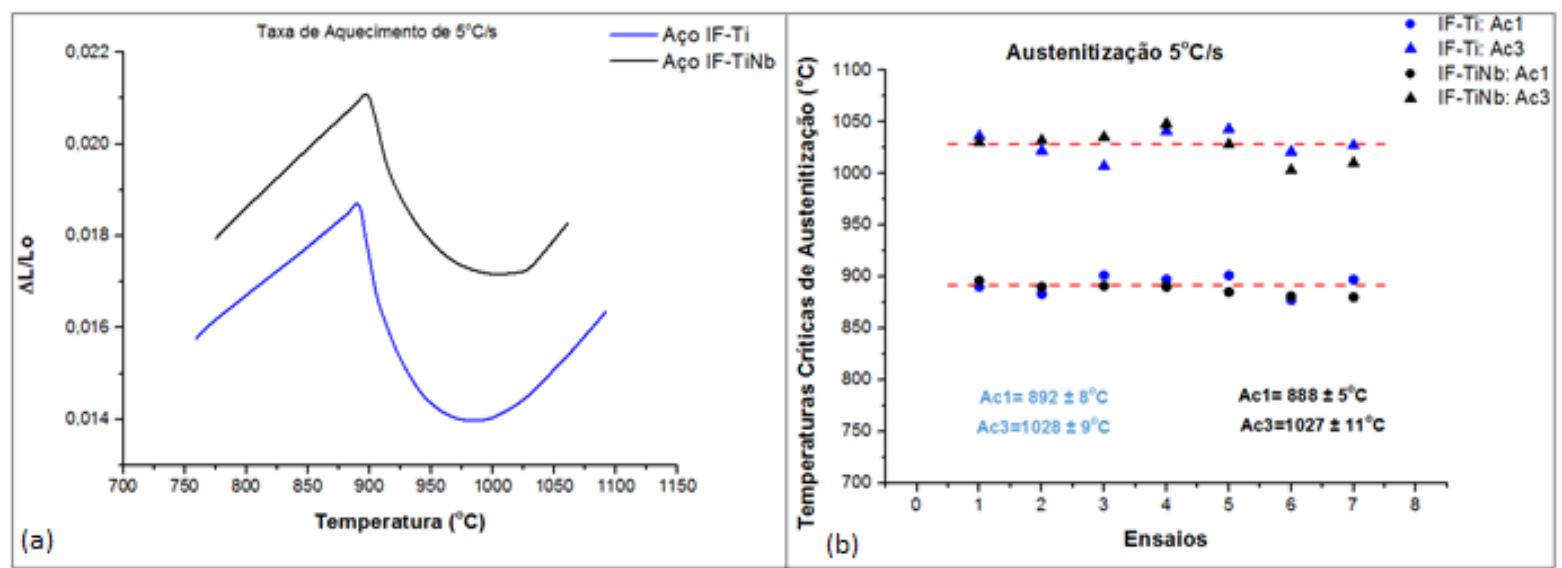

Figura 4 - (a) Curvas dilatométricas de aquecimento contínuo a $5^{\circ} \mathrm{C} / \mathrm{s}$ dos aços IF-Ti e IF-TiNb; (b) Temperaturas críticas Ac1 e Ac3 dos aços IF-Ti e IF-TiNb.

\subsubsection{Resfriamento Contínuo}

A Figura 5 (a) apresenta as curvas dilatométricas de resfriamento contínuo a $0,5^{\circ} \mathrm{C} / \mathrm{s}$ dos aços IF-Ti e IF-TiNb. A Figura 5 (b) apresenta as temperaturas críticas de início e fim da decomposição da austenita em função das diferentes taxas de resfriamento. Semelhante ao aquecimento, as temperaturas críticas de início e fim de transformação $\gamma \rightarrow \alpha$ foram determinadas aplicando-se o método das derivadas [13]. Durante o resfriamento, grãos de $\alpha$ nucleiam-se preferencialmente nos contornos de grãos da $\gamma$ à temperatura Ar3 e então crescem continuamente, consumindo toda a austenita[3].

Observa-se que as temperaturas Ar3 e Ar1 do aço IF-TiNb são menores do que as temperaturas obtidas para o aço IF-Ti. Segundo a literatura, para a concentração de $\mathrm{Nb}$ presente no aço IF-TiNb, na temperatura de austenitização avaliada neste trabalho, haverá parcial dissolução de $\mathrm{NbC}$ na austenita. $\mathrm{O} \mathrm{Nb}$ em solução sólida, apesar de ser $\alpha$-gêneo, e a sua reprecipitação dificultam o processo difusional, dificultando a decomposição da austenita. Kim et al. (2013) cita alguns trabalhos que demonstram que a formação da ferrita $(\alpha)$ retardou-se com o aumento da concentração de $\mathrm{Nb}$ em aços baixo carbono microligados ao $\mathrm{Nb}[8-9,15]$. O maior teor de Mn neste aço também é uma importante contribuição para este abaixamento das temperaturas críticas. $\mathrm{O} M n$ é um elemento $\gamma$-gêneo e, portanto, retarda a decomposição da $\gamma$. 
Com a diminuição da temperatura de início de transformação,espera-se que o raio crítico de nucleação de $\alpha$ diminua, promovendo assim um maior número de núcleos da nova fase aptos ao crescimento. Neste contexto, espera-se que os grãos ferríticos do aço IF-TiNb sejam menores quando comparados com os aços IF-Ti para as diferentes taxas de resfriamento estudadas [9].

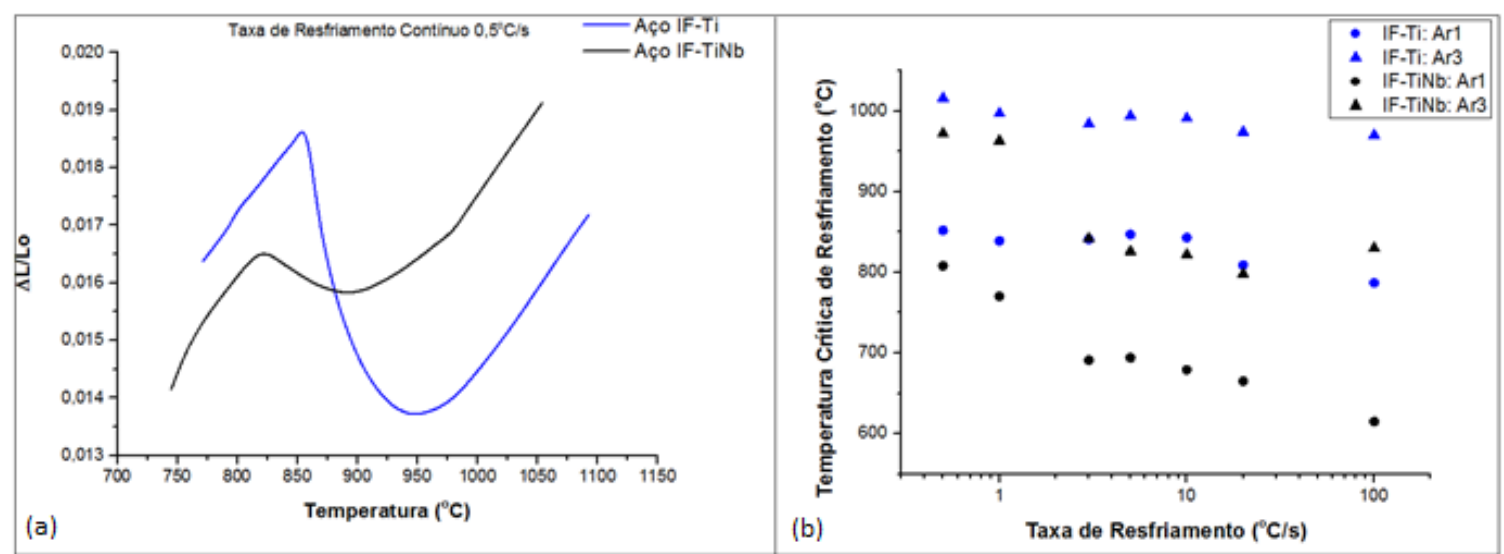

Figura 5 - (a) Curva dilatométrica de resfriamento contínuo a $0,5^{\circ} \mathrm{C} / \mathrm{s}$ dos aços IF-Ti e IF-TiNb; (b) Temperaturas críticas de transformação durante resfriamento em função da taxa de resfriamento.

\subsubsection{Comparativo entre as cinéticas de transformação $\gamma \rightarrow \alpha$ dos aços IF durante resfriamento contínuo}

A Figura 6 (a) e (c) apresentam a cinética de decomposição da austenita durante o resfriamento contínuo para os aços IF-Ti e IF-TiNb, respectivamente. O cálculo da fração de austenita decomposta foi feito por meio da aplicação do método da variação específica de volume (regra da alavanca) [16]. Enquanto que a Figura 6 (b) e (d) apresenta a velocidade de transformação em função da temperatura, ou seja, indiretamente em função do grau de super-resfriamento, uma vez que quanto menor a temperatura de transformação, maior o grau de super-resfriamento.

A transformação $\gamma \rightarrow \alpha$ é um processo termicamente ativado. A teoria clássica do complexo ativado sugere que as energias livres da fase reagente e da fase produto estão nas duas posições mínimas de energia livre, separadas por uma energia máxima no estado metaestável (complexo de ativação). A taxa de transformação ou a cinética da reação nesses casos depende de dois fatores: (i) a magnitude da barreira de energia de ativação, sendo a maior taxa para uma barreira de ativação menor e (ii) o número de átomos no sistema reagente com energia térmica suficientemente alta para superar a barreira de ativação [17].

No caso de aços microligados, como os aços IF, é importante identificar a influência dos elementos dissolvidos e das impurezas no grau de super-resfriamento produzido durante a transformação $\gamma \rightarrow \alpha$. A causa deste super-resfriamento reside na rejeição de soluto pela fase $\alpha$, enriquecendo consequentemente a fase $\gamma$ junto à interface durante a transformação. Nota-se que quanto mais baixa a temperatura de transformação, como no caso do aço IF-TiNb, maior será o grau de superresfriamento e, portanto, menor o raio crítico de nucleação, o que favorece um refino da estrutura ferrítica.

Para taxas de resfriamento fora das condições de equilíbrio, o relaxamento dos estados de energia de valores elevados para baixos é incapaz de manter o ritmo de decréscimo com a velocidade de redução da temperatura. Como resultado, mesmo que a temperatura diminua, a fração de átomos com energia térmica alta o suficiente 
para permitir que eles superem a barreira de ativação será maior do que a fração esperada em condições de equilíbrio, favorecendo a velocidade de transformação. Esta diferença entre a fração real de átomos e a fração de equilíbrio aumentará com a taxa de resfriamento crescente. Esta diferença é equivalente a uma redução efetiva na energia de ativação aparente com a taxa de resfriamento. Entretanto, na sequência do resfriamento, à medida que se atinge temperaturas de transformação baixas, a energia disponível para o crescimento da fase produto diminui e há um decréscimo na velocidade de transformação. Estas observações explicam o perfil parabólico das curvas de velocidade de transformação versus temperatura (Fig. 6 (a) e (c)), onde se nota inicialmente uma velocidade crescente que atinge um valor máximo e decresce até o final da transformação [17-18].

A Figura 7 apresenta as curvas da cinética de decomposição da austenita em função do tempo de transformação para cada condição de resfriamento para os aços (a) IFTi e (b) IF-TiNb.Observa-se, a partir das Fig.6 e 7, que o aço IF-TiNb é relativamente mais sensível ao efeito da taxa de resfriamento do que o aço IF-Ti, pois com o aumento da taxa de resfriamento há menos tempo para os átomos se difundirem e a maior quantidade de $\mathrm{Nb}$ e $\mathrm{Mn}$ dissolvidos em solução sólida no aço IF-TiNb irá ter uma influência ainda maior no atraso da decomposição austenítica.
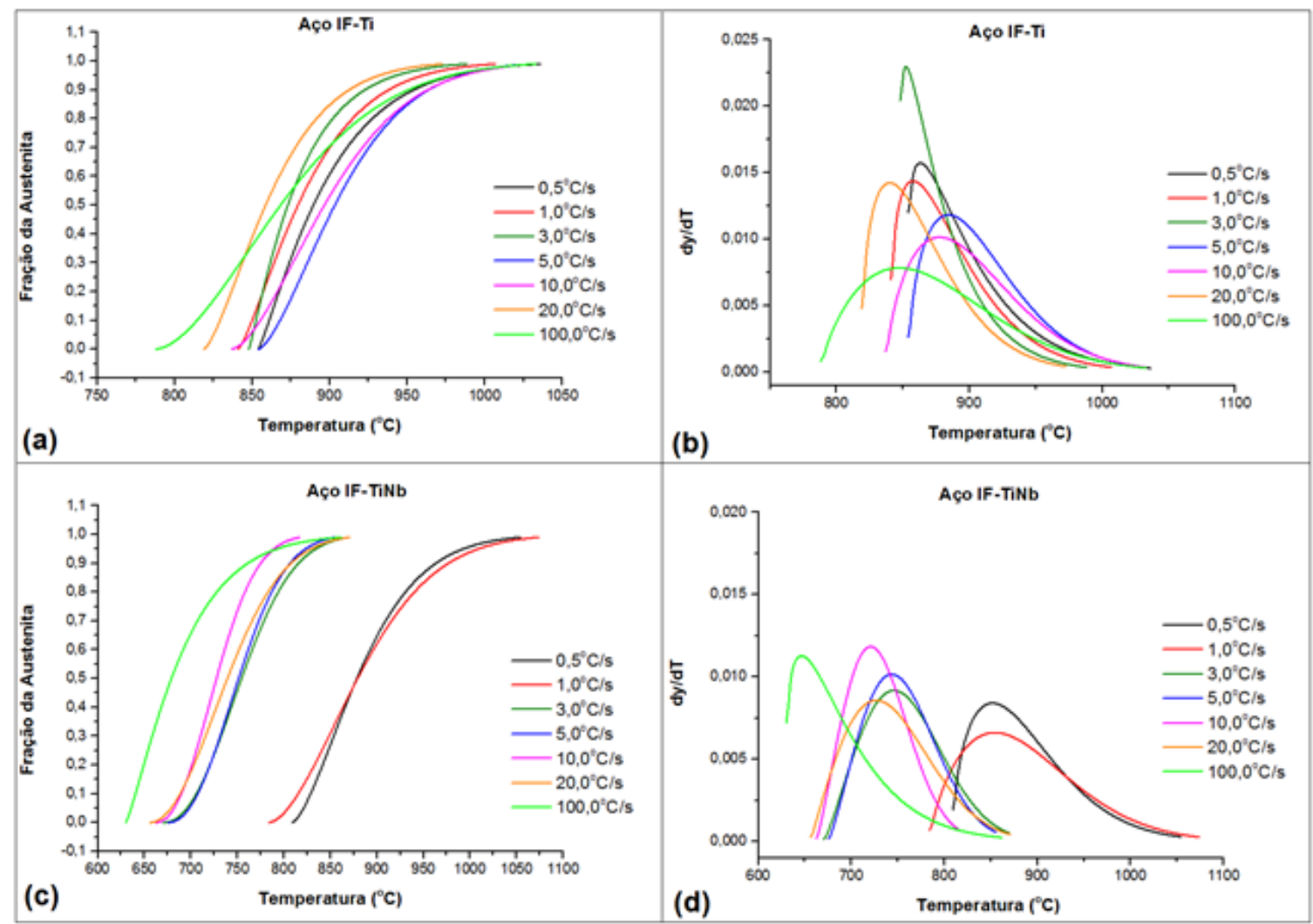

Figura 6 - (a) e (c)Fração da austenita em função da temperatura para o aço IF-Ti e IF-TiNb, respectivamente; (b) e (d) Velocidade de decomposição da austenita em função da temperatura para o aço IF-Ti e IF-TiNb, respectivamente. 


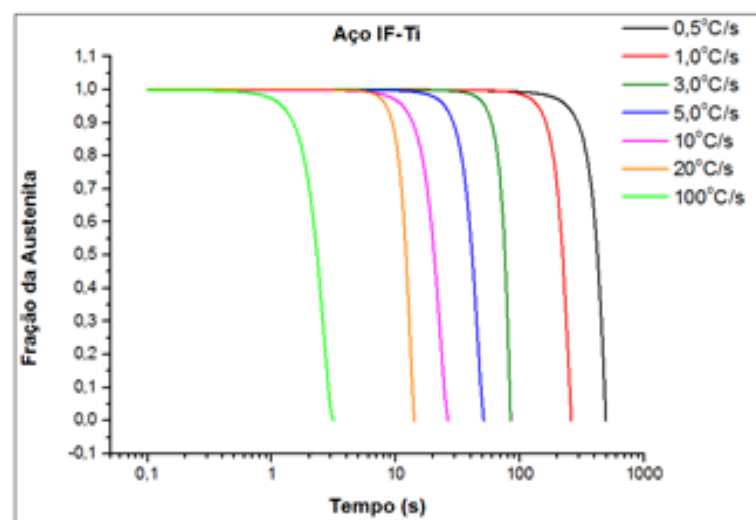

(a)

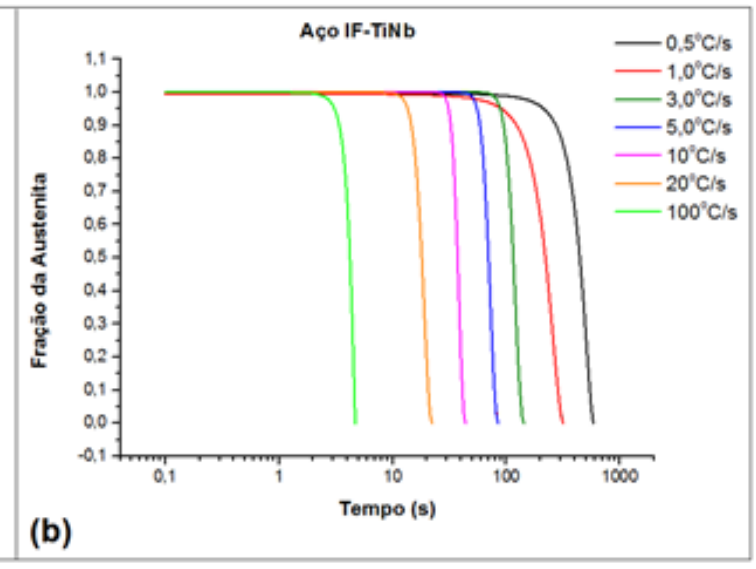

Figura 7 - Cinética de decomposição da austenita em função do tempo (a) Aço IF-Ti e (b) Aço IF$\mathrm{TiNb}$.

\subsubsection{Diagramas TRC}

Por meio da análise das temperaturas críticas de transformação medidas nas curvas dilatométricas correspondentes às taxas de resfriamento $(0,5 ; 1,0 ; 3,0 ; 5,0 ; 10 ; 20$ e $100^{\circ} \mathrm{C} / \mathrm{s}$ ), foi possível determinar os diagramas TRC dos aços IF-Ti e IF-TiNb. A Figura 8 apresenta um comparativo entre os diagramas obtidos para os dois aços. Nota-se que para taxas de resfriamento contínuas acima de $3^{\circ} \mathrm{C} / \mathrm{s}$, a temperatura final de transformação $\gamma \rightarrow \alpha$ para o aço IF-Ti é próxima à temperatura de início de transformação para o aço IF-TiNb. Isto porque, conforme dito anteriormente, a maior concentração de $\mathrm{Mn}$ ( $\gamma$-gêneo) no aço IF-TiNb contribuirá fortemente para o atraso do início de transformação $\gamma \rightarrow \alpha$, sendo este efeito mais pronunciado em taxas de resfriamento acima de $3^{\circ} \mathrm{C} / \mathrm{s}$.

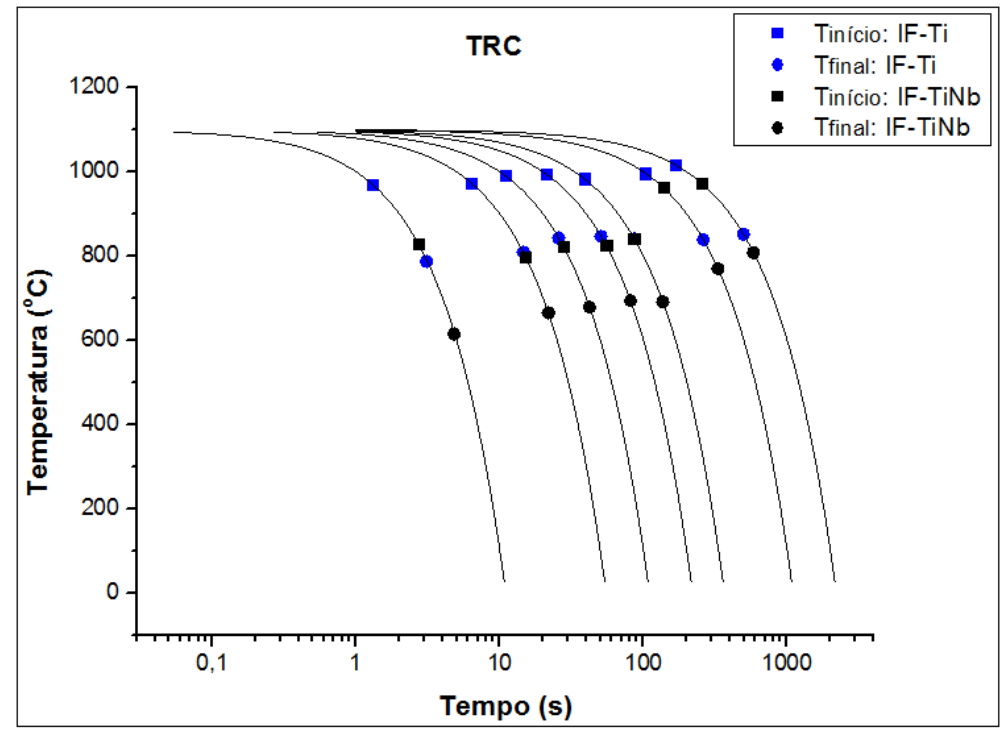

Figura 8 - Comparativo dos Diagrama TRC dos aços IF-Ti e IF-TiNb.

\subsubsection{Caracterização Microestrutural dos Corpos de Prova de Dilatometria}

A Figura 9 apresenta as microestruturas dos corpos de provas dos aços IF submetidos aos ensaios dilatométricos com taxa de resfriamento de $0,5^{\circ} \mathrm{C} / \mathrm{s}$ e $100^{\circ} \mathrm{C} / \mathrm{s}$. Nota-se a obtenção de uma estrutura mais grosseira para o aço IF-Ti, tanto para a taxa de $0,5^{\circ} \mathrm{C} / \mathrm{s}$ quanto para $100^{\circ} \mathrm{C} / \mathrm{s}$, constituída por ferrita e finos 
precipitados, cujo os tamanhos de grão ferríticos médio são $74,5 \mu \mathrm{m}$ e $57,6 \mu \mathrm{m}$ respectivamente. Enquanto que a microestrutura do aço IF-TiNb, também composta de ferrita, se apresenta muito mais refinada com tamanho de grão de $43,8 \mu \mathrm{m}$ para a condição de resfriamento de $0,5^{\circ} \mathrm{C} / \mathrm{s}$. Em relação à condição de resfriamento de $100^{\circ} \mathrm{C} / \mathrm{s}$ para o aço IF-TiNb, observa-se, além ferrita, a presença de um constituinte formado a partir da precipitação de carbonetos de nióbio em estruturas ferríticas irregulares, descrito por alguns autores como uma espécie de transformação bainítica [7-9].
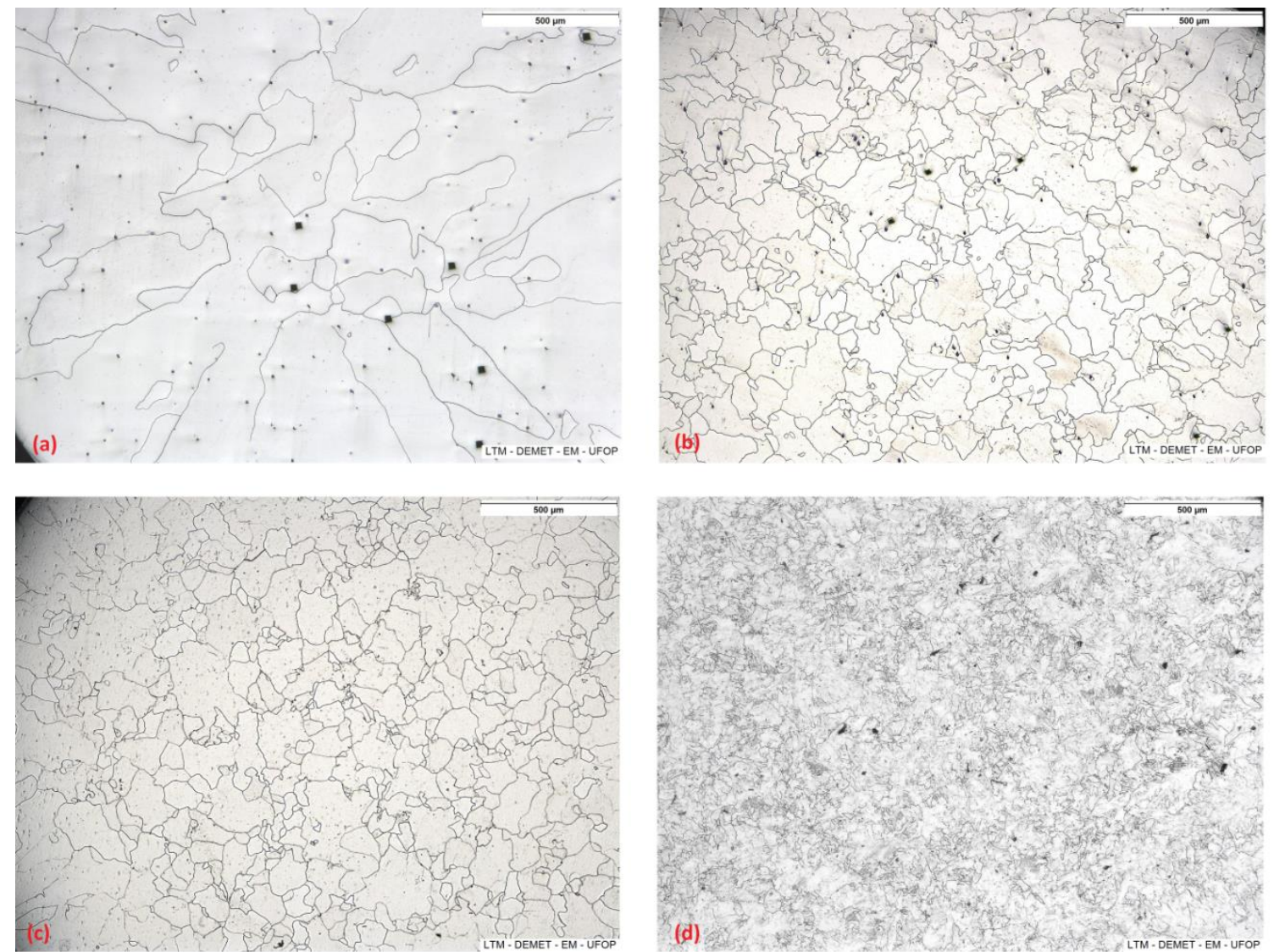

Figura 9 - Microestrutura dos corpos de provas dilatométricos - MO - Nital 2\% - aumento de 50x: (a) Aço IF-Ti - taxa de resfriamento de $0,5^{\circ} \mathrm{C} / \mathrm{s}$; (b) Aço IF-Ti - taxa de resfriamento de $100^{\circ} \mathrm{C} / \mathrm{s}$; (c) Aço

IF-TiNb - taxa de resfriamento de $0,5^{\circ} \mathrm{C} / \mathrm{s}$; (d) Aço IF-TiNb - taxa de resfriamento de $100^{\circ} \mathrm{C} / \mathrm{s}$.

A Figura 10 apresenta a média dos valores de microdureza Vickers obtidos para os corpos de provas provenientes dos ensaios dilatométricos. Nota-se que a microdureza aumenta à medida que a taxa de resfriamento aumenta. Além disso, pode-se observar que os valores de microdureza para o aço IF-TiNb em todas as condições de resfriamento são maiores em comparação com os do aço IF-Ti, isto porque a maior densidade de contornos de grãos na microestrutura do aço IF-TiNb faz com que sua resistência mecânica seja maior do que do aço IF-Ti, além da contribuição do endurecimento por precipitação das finas partículas de $\mathrm{NbC}$ formadas no aço IF-TiNb. 


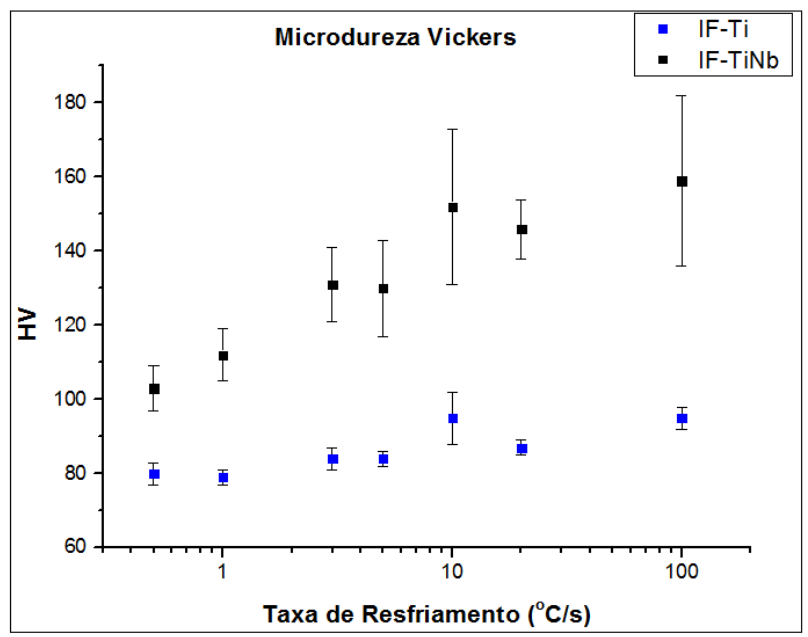

Figura 10 - Microdureza das amostras dos aços IF-Ti e IF-TiNb submetidas aos ensaios dilatométricas em diferentes condições de resfriamento contínuo.

\section{CONCLUSÃO}

Os aços IF apresentam diferenças significativas na quantidade do elemento estabilizante e do elemento Mn. Ambos os aços no estado de entrega são constituídos por uma matriz ferrítica, sendo que o aço IF-TiNb apresenta uma microestrutura mais refinada.

Quanto à cinética de austenitização, pode-se observar que as médias das temperaturas críticas durante o aquecimento contínuo para o aço IF-TiNb são ligeiramente menores em relação às do aço IF-Ti.

As temperaturas críticas medidas durante o resfriamento contínuo do aço IF-TiNb são menores do que as temperaturas obtidas para o aço IF-Ti em função da dissolução parcial de carbonetos de nióbio e do seu maior teor de Mn.

$\mathrm{O}$ aço IF-TiNb se mostrou ser mais sensível ao efeito da taxa de resfriamento. A maior concentração de $\mathrm{Mn}$ no aço IF-TiNb contribui para o atraso da decomposição austenítica, sendo este efeito mais pronunciado em taxas de resfriamento acima de $3^{\circ} \mathrm{C} / \mathrm{s}$.

Quanto à caracterização microestrutural e de microdureza dos corpos de provas dilatométricos, observou-se que quanto maior a velocidade de resfriamento, menor 0 tamanho de grão ferrítico, sendo este efeito maios pronunciado no aço IF-TiNb. Os finos precipitados formados nos aços IF-TiNb e a maior densidade de contornos de grãos nesses aços contribuíram para a obtenção de maiores valores de microdurezas Vickers.

\section{Agradecimentos}

À Capes, pelo financiamento da bolsa de mestrado.

\section{REFERÊNCIAS}

1. Bhadeshia, H.K.D.H.; Phase Transformations during Spot Welding of Interstitial-Free Steel. In: Proceedings of the International Conference on Interstitial-free Steels, 2010, Jamshedpur, India. 11p.

2. Beladi, H. e Rohrer,G.S. The Distribution of Grain Boundary Planes in Interstitial Free Steel. The Minerals, Metals \& Materials Society and ASM International, v.44A, p.115-124, 2013.

3. Ghosh, S.; Singh,A.K.; Mula, S. Effect of critical temperatures on microstructures and mechanical properties of $\mathrm{Nb}$-Ti stabilized IF steel processed by multiaxial forging. Materials and Design, v.100, p.47-57, 2016. 
4. Deardo, A.J., Physical Metallurgy of Interstitial-Free Steels: Precipitates and Solutes, in IF Steel 2000, ISS, Warrendale, PA, 2000, p.125-136.

5. Fonseca, F.A.V.; Efeito do Substrato dos Aços IF nas Propriedades do Revestimento Galvannealed. 2006. 118p. Dissertação apresentada à Escola de Engenharia Metalúrgica e de Minas da UFMG para obtenção do Título de Mestre em Engenharia, Belo Horizonte, 2006.

6. Saray, O.; Purcek, G.; Karaman, I.; Neindorf, T.; Maier, H.J.; Equal-channel angular sheet extrusion of interstitial-free (IF) steel: Microstructural evolution and mechanical properties. Materials Science and Engineering A, v.528, p.6573-6583, 2011.

7. Tither, G.; Garcia, C.I.; Hua, M. and Deardo, A.J., Precipitation Behavior and Solute Effects in Interstitial-Free Steels Sheets, in International Forum for Physical Metallurgy of IF Steels, ISIJ, Tokyo, 1994, p. 293-322.

8. Lips, K.; Yang, X.; Mols, K.; The Effect of coiling temperature and continuous annealing on the properties of bake hardenable IF Steels, Steel research, 67, 1996, n.9, p.357-363.

9. Mohrbacher, H.; Niobium Based Metallurgical Concepts and Strategies for the Production of IF-HS and IF-BH Steel Grades. International Conference on Interstitial Free Steels: Manufacturing Applications IFSTEEL-2010, Jamshedpur, India, 12p., 2010.

10.Dias, F.M.S.; Fonseca, F.A.V.; Hauegen, C.G.; Lins, J.F.C.; Campos, M.F. Textura e Comportamento Mecânico de Aços IF Estabilizados ao Ti e Nb-Ti. Tecnologia em Metalurgia, Materiais e Mineração, São Paulo, v.9, n.4, p.294301, 2012.

11. Bayraktar, E.; Chevalier, J.P.; Kaplan, D.; Devillers, L. Effect of Alloying Elements on the Damage of Interstitial Free Steels. In: Proceedings of the SEM Annual Conference, 2009, Albuquerque New Mexico USA. Society for Experimental Mechanics Inc, 2009.

12. Calcagnotto, M.; Ponge, D.; Raabe, D. On the Effect of Manganese on Grain Siza Stability and Hardenability in Ultrafina-Grained Ferrite/Martensite DualPhase Steels. Metallurgical and Materials Transactions,v.43A, n.1, p.37-46, 2012.

13. Pawlowski, B.; Determination of Critical Points of Hypoeutectoid Steel. Archives of Metallurgy and Materials, v.57, p.957-962, 2012.

14. Zhang, G., Chae, J., Kim, K., Suh, D.W. Effects of Mn, Si and Cr addition on the dissolution and coarsening of pearlitic cementite during intercriticalaustenitization in Fe-1mass\% alloy. Materials Characterization. 2013; 81:56-67.

15. Kim, J.; Jung, J.G.; Kim, D.H.; Lee, Y.K.; The kinetics of $\mathrm{Nb}(\mathrm{C}, \mathrm{N})$ precipitation during the isothermal austenite to ferrite transformation in a low-carbon $\mathrm{Nb}$ microalloyed steel. Acta Materialia, v.61, p.7437-7443, 2013.

16.Suh, D.W.; Oh, C.S.; Han, H.N.; Kim, S.J. Dilatometric analysis of austenite decomposition considering the effect of non-isotropic volume change. Acta Materialia, v.55, Fevereiro/2007. p.2659-2669. Disponível em: www.sciendedirect.com. Acesso em: Novembro/2016.

17.Singh, S.B.; Krishnan, K.; Sahay, S.S.; Modeling non-isothermal austenite to ferrite transformation in low carbon steels. Materials Science and Engineering A, v.445-446, p.310-315, 2007. 
18. Gómez, M.; Medina, S. F.; Caruana, G. Modelling of Phase Transformation Kinetics by Correction of Dilatometry Results for a Ferritic Nb-microalloyed Steel. ISIJ International, v.43, no8, p.1228-1237, Fevereiro/2003. 